\title{
Rancang Bangun Alat Praktikum Perpindahan Panas Konveksi Paksa pada Pin Fin Berpenampang Sirkular Susunan Staggered
}

\author{
Alik Dinikavanila dan Budi Utomo Kukuh Widodo \\ Departemen Teknik Mesin, Fakultas Teknologi Industri \\ Institut Teknologi Sepuluh Nopember (ITS) 60111 Indonesia \\ e-mail: buditem@me.its.ac.id
}

\begin{abstract}
Abstrak-Fin digunakan untuk meningkatkan perpindahan panas dengan menambah luasan atau area perpindahan panas yang disebut extended surface. Salah satu media untuk mendemonstrasikan perpindahan panas pada fin adalah alat praktikum yang juga dapat digunakan untuk mengetahui pengaruh diameter fin dan kecepatan udara terhadap perpindahan panas konveksi serta distribusi temperatur di sepanjang fin. Pengujian dilakukan dengan menggunakan circular pin fin dengan diameter $10 \mathrm{~mm}$ dan $16 \mathrm{~mm}$ serta panjang $70 \mathrm{~mm}$. Pin fin diletakkan dalam rectangular duct dan disusun secara staggered dengan $S_{T}=20 \mathrm{~mm}, S_{L}=20 \mathrm{~mm}$, dan $S_{D}=23 \mathrm{~mm}$. Electric plate heater diletakkan pada base plate sebagai sumber panas dan dikontrol pada $\mathrm{T}=5^{\circ} \mathrm{C}$. Kecepatan udara divariasikan dengan menggunakan variasi air inlet pada centrifugal blower. Pengukuran temperatur dilakukan dengan menggunakan termokopel dan akuisisi data yang terintegrasi pada komputer. Hasil penelitian menunjukkan distribusi temperatur menurun di sepanjang fin. Pada kecepatan yang sama, fin $10 \mathrm{~mm}$ mempunyai koefisien konveksi yang lebih besar daripada fin $16 \mathrm{~mm}$.
\end{abstract}

Kata Kunci-Circular Pin Fin, Extended Surface, Konveksi Paksa, Koefisien Konveksi, Susunan Staggered.

\section{PENDAHULUAN}

$\mathrm{E}$ xtended surface berfungsi meningkatkan perpindahan panas dengan cara menambah luasan atau area perpindahan panas. Perpindahan panas dipengaruhi oleh bentuk geometri, kondisi aliran, dan properties fluida. Kenaikan kecepatan udara menyebabkan peningkatan Nusselt number dan koefisien perpindahan panas konveksi. Oleh karena itu, laju perpindahan panas fin semakin besar dengan naiknya kecepatan udara. Selain itu, peningkatan kecepatan udara menyebabkan tekanan udara yang melalui pin fin naik secara signifikan [1].

Pemanfaatan fin menjadi lebih maksimal apabila material dari fin mempunyai konduktivitas termal yang baik. Pada rentang nilai Reynolds number yang sama, laju perpindahan panas terbesar dicapai oleh copper, kemudian brass, aluminium, dan steel. Nusselt number meningkat dengan kenaikan Reynolds number, sehingga koefisien dan laju perpindahan panas juga meningkat [2].

Susunan pin fin memengaruhi besar perpindahan panas. Kenaikan mass flow rate, $S_{x}$, dan $S_{y}$ dapat memperbaiki perpindahan panas. Peningkatan Nusselt number terjadi pada $S_{y}$ dan $S_{x}$ tertentu. Susunan staggered menghasilkan peningkatan perpindahan panas yang lebih baik daripada susunan aligned. Namun penurunan tekanan pada susunan staggered lebih besar daripada susunan aligned. Selain itu, bentuk fin yang memiliki Nusselt number yang paling tinggi adalah bentuk diamond, kemudian square, dan cylinder.
Friction factor yang terjadi pada susunan staggered lebih besar daripada susunan aligned [3].

Penelitian ini akan membahas perancangan alat praktikum perpindahan panas konveksi paksa melalui berkas pin fin berpenampang sirkular dan pengaruh variasi diameter serta kecepatan fluida terhadap perpindahan panas konveksi paksa yang terjadi.

\section{URAIAN PENELITIAN}

Perpindahan panas konveksi dapat diklasifikasikan berdasarkan aliran fluida, yaitu konveksi alami dan konveksi paksa. Konveksi alami terjadi ketika aliran fluida bergerak akibat bouyancy force atau efek gaya apung, sedangkan konveksi paksa terjadi karena aliran fluida digerakkan oleh daya eksternal seperti kipas, pompa, atau angin. Besar perpindahan panas konveksi dapat dihitung dengan Newton's law of cooling berikut ini,

$$
q=\bar{h} \cdot A \cdot \Delta T
$$

Koefisien konveksi $(\bar{h})$ dapat dihitung dengan menggunakan korelasi Nusselt number. Nusselt number merupakan bilangan tak berdimensi yang menyatakan temperature gradient di sepanjang permukaan. Hubungan antara Nusselt number dan koefisien perpindahan panas konveksi secara paksa pada aliran eksternal dapat dilihat dari Persamaan 2.

$$
N u=\frac{\bar{h} D}{k_{f}}=f(\operatorname{Re}, \operatorname{Pr})=C \operatorname{Re}^{m} \operatorname{Pr}^{n}
$$

Konstanta $C, m$, dan $n$ besarnya ditentukan oleh geometri permukaan dan jenis aliran fluida. Nilai $n$ untuk geometri permukaan silinder adalah 1/3 [4].

Perpindahan panas konveksi paksa khususnya yang terjadi pada sirip banyak diaplikasikan pada dunia industri seperti heat exchanger, sistem pendinginan ruangan, dan pada dunia elektronik yaitu heat sink. Pada penelitian ini digunakan bentuk sirip sirkular, yang disusun secara staggered. Peralatan yang dirancang bangun ini tersusun atas circular pin fin, rectangular duct, sistem pemanas, honeycomb dan difuser, centrifugal blower, hot wire anemometer, digital thermocontrol, dan sistem akuisisi data.

\section{A. Circular pin fin}

Pin fin yang digunakan berpenampang sirkular dengan variasi dimensi $10 \mathrm{~mm}$ dan $16 \mathrm{~mm}$ serta panjang fin sebesar $70 \mathrm{~mm}$. Circular pin fin akan disusun dengan susunan selangseling (staggered) dan diuji dalam rectangular duct. Jarak spasi pada susunan yaitu $S_{T}=20 \mathrm{~mm}, S_{L}=20 \mathrm{~mm}$, dan $S_{D}=$ $23 \mathrm{~mm}$. Fin terbuat dari aluminium alloy seperti pada Gambar 
1. Pengujian dilakukan pada vertical rectangular duct dengan dimensi panjang $159 \mathrm{~mm}$, lebar $90 \mathrm{~mm}$, dan tinggi $716 \mathrm{~mm}$. Fin diletakkan pada base plate berdimensi $100 \mathrm{~mm}$ x $100 \mathrm{~mm}$ dan dipasangkan pada rectangular duct yang berjarak 350 mm dari atas.
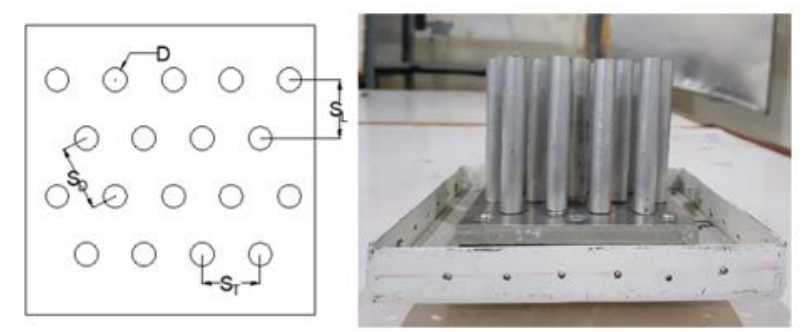

Gambar 1. Skema pin fin susunan staggered

\section{B. Rectangular duct}

Rectangular duct merupakan wind tunnel yang berfungsi sebagai ruang uji. Circular pin fin diletakkan di dalam rectangular duct dan dialiri udara dari centrifugal blower. Rectangular duct diposisikan secara vertikal. Bahan yang digunakan untuk membuat rectangular duct adalah steel dan acrylic untuk sisi depan. Dimensi yang dimiliki rectangular duct yaitu, panjang $159 \mathrm{~mm}$, lebar $90 \mathrm{~mm}$, dan tinggi 716 $\mathrm{mm}$.

\section{Sistem pemanas}

Berkas fin dipanasi dengan constant heat flux, yaitu dengan pemanasan plate heater secara konstan pada temperatur $50^{\circ} \mathrm{C}$. Jenis heater yang digunakan pada penelitian ini adalah plate heater. Plate heater diletakkan di bawah base plate dengan dimensi $100 \mathrm{~mm}$ x $100 \mathrm{~mm}$. Gambar 2 merupakan plate heater yang digunakan dalam penelitian. Material plate heater adalah stainless steel, dengan voltase $220 \mathrm{~V}$ dan power sebesar 150W.

Gambar 2. Plate heater

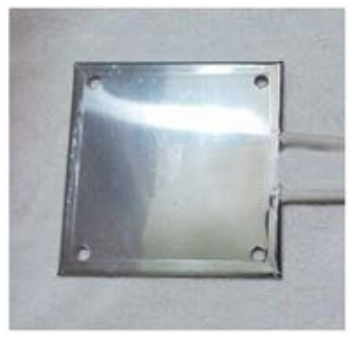

\section{Honeycomb dan difuser}

Flow straightener merupakan pelurus aliran yang sering digunakan di dalam wind tunnel. Pelurus aliran ini sering disebut honeycomb yang dipasang sejajar dalam arah aliran. Honeycomb yang digunakan memiliki panjang $19 \mathrm{~mm}$ dan diameter 3 mm. Difuser digunakan untuk menghubungkan aliran udara dari centrifugal blower menuju rectangular duct. Difuser yang digunakan berdimensi 80 mm x 80 mm dan 100 mm x 160 mm dengan tinggi $97 \mathrm{~mm}$.

\section{E. Centrifugal Blower}

Centrifugal blower digunakan untuk mengalirkan udara ke dalam rectangular duct. Kecepatan udara divariasikan dengan cara mengubah luasan air inlet pada centrifugal blower. Kecepatan udara diukur dengan menggunakan hot wire anemometer, sehingga didapatkan kecepatan udara ratarata sebesar $2.64 \mathrm{~m} / \mathrm{s} ; 3.65 \mathrm{~m} / \mathrm{s} ; 3.95 \mathrm{~m} / \mathrm{s}$; dan $4.2 \mathrm{~m} / \mathrm{s}$.

\section{F. Digital thermocontrol}

Digital thermocontrol digunakan untuk mengendalikan temperatur pengujian. Prinsip kerja termokontrol yaitu ketika telah mencapai temperatur tertentu, maka elemen pemanas atau heater akan mati secara otomatis dan ketika temperatur di bawah temperatur yang ditentukan heater akan menyala secara otomatis.

\section{G. Sistem akuisisi data}

Pengukuran temperatur permukaan fin dengan menggunakan perangkat akuisisi data DAQ MX 100 dan termokopel tipe K sebagai sensor temperatur. DAQ MX 100 adalah perangkat akuisisi data yang dilengkapi oleh software yang terdiri dari integration monitor, viewer, dan calibrator. Integration monitor menampilkan hasil pengukuran dalam setiap channel, pengaturan komputasi pengukuran, dan menyimpan data pengukuran. Hasil pengukuran yang telah disimpan dapat ditampilkan, dibaca, dan disajikan dalam bentuk statistical computation. Penyimpanan hasil pengukuran dapat berupa file seperti Excel. Hal ini dapat dilakukan pada bagian viewer, sedangkan calibrator digunakan untuk input module dan output module MX 100. Input sensor yang dapat digunakan pada DAQ MX 100 bermacam-macam yaitu tegangan (DC Voltage), TC (Thermocouple), RTD (Resistance Temperature Detector), RTDEX (Resistance Temperature Detector), OHM (Resistance), DI (Digital Input), dan RRJC (TC).

Pengukuran temperatur dilakukan pada base plate, permukaan fin pada $\mathrm{x}=35 \mathrm{~mm}$ dan $\mathrm{x}=70 \mathrm{~mm}$, temperatur udara masuk, dan temperatur udara keluar. Pengambilan data dilakukan selama 30 menit. Posisi pengukuran temperatur fin dan skema alat uji dapat dilihat pada Gambar 3 dan Gambar 4.
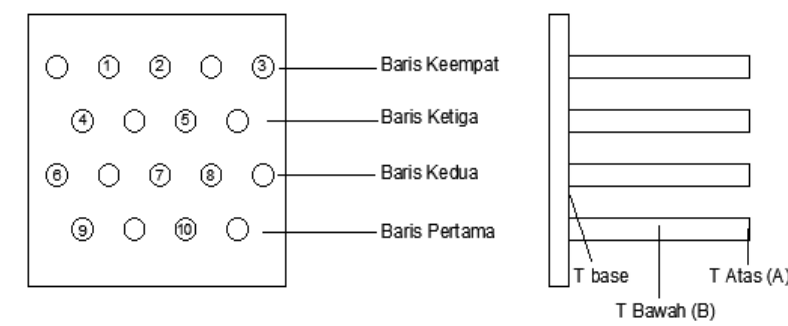

Gambar 3. Baris dan tempat pengukuran temperatur permukaan fin

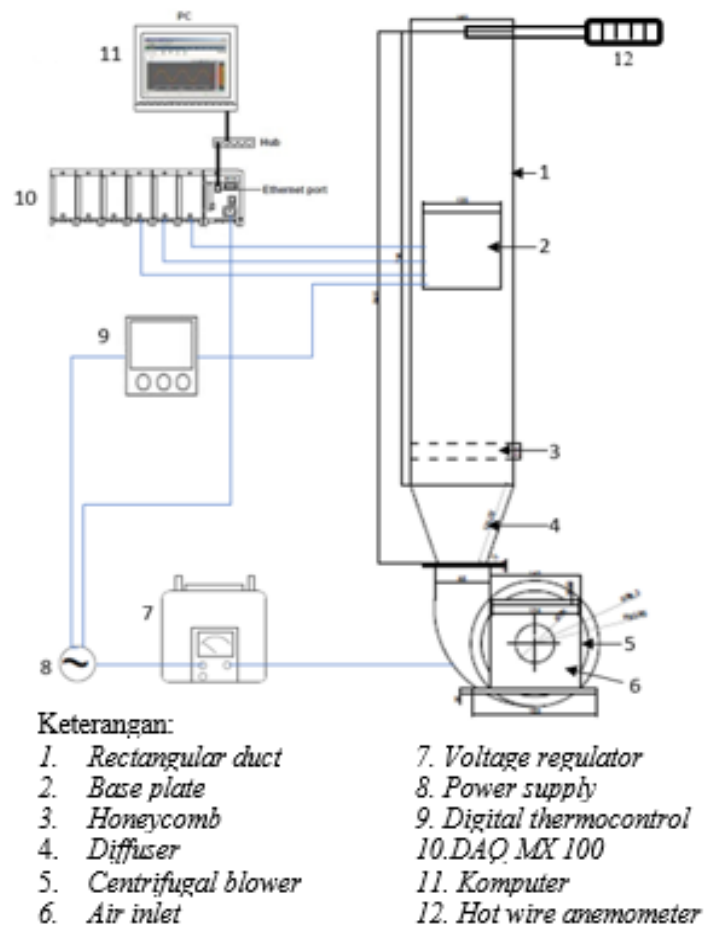

Gambar 4. Skema alat uji 
Perhitungan perpindahan panas pada penelitian ini menggunakan kesetimbangan energi dalam kondisi steady state. Gambar 5 merupakan control volume pada skema alat uji untuk analisis heat balance.

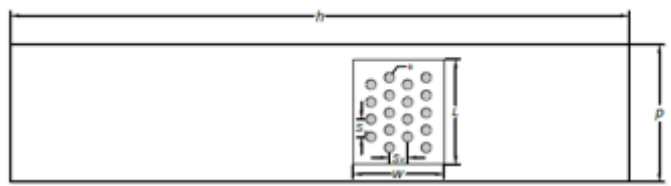

(a)

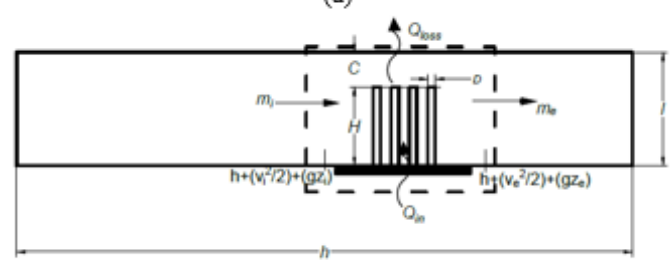

(b)

Gambar 5. Control volume untuk analisis heat balance (a) Tampak depan (b) Tampak samping

Dari analisis heat balace, perpindahan panas yang terjadi pada ducting dapat dihitung dengan persamaan 1 .

$$
\dot{Q}_{\text {in }}=\dot{m} c_{p}\left(T_{\text {out }}-T_{\text {in }}\right)
$$

dan $\dot{m}$ dihitung dengan persamaan berikut:

$$
\dot{m}=\rho A_{f f} V
$$

dengan $\dot{m}$ merupakan mass flow rate yang dapat digunakan untuk menghitung Reynolds number,

$$
\operatorname{Re}=\frac{\left(\dot{m} / A_{f f}\right) D}{\mu}
$$

Free flow area $\left(A_{f f}\right)$ merupakan area atau luasan yang dilewati oleh aliran udara. $A_{f f}$ dirumuskan sebagai berikut:

$$
A_{f f}=p l-N_{x} H D
$$

dengan $N_{x}$ adalah jumlah fin arah transversal.

Perpindahan panas konveksi dari permukaan fin dan base plate dapat dihitung dengan persamaan berikut ini:

$$
Q_{\text {CONV }}=\bar{h} A_{s}\left[T_{b}-\left(\frac{T_{\text {in }}+T_{\text {out }}}{2}\right)\right]
$$

dengan $T_{\text {in }}$ dan $T_{\text {out }}$ merupakan temperatur udara inlet dan outlet, $T_{b}$ adalah temperatur rata-rata base plate, dan $A_{s}$ adalah luas permukaan total dari base dan fin.

$$
A_{s}=W L+\pi D H N_{x y}
$$

$W$ dan $L$ merupakan panjang dan lebar base plate, $D$ adalah diameter fin, $H$ adalah panjang fin, dan $N_{x y}$ merupakan jumlah fin.

Koefisien perpindahan panas rata-rata dapat dihitung dengan substitusi persamaan 3 dan 7, sehingga diperoleh nilai koefisien rata-rata sebagai berikut [3]:

$$
\bar{h}=\frac{\dot{m} c_{p}\left(T_{\text {out }}-T_{\text {in }}\right)}{A_{s}\left[T_{b}-\left(\frac{T_{\text {out }}+T_{\text {in }}}{2}\right)\right]}
$$

\section{HASIL DAN PEMBAHASAN}

Penelitian dilakukan untuk mengetahui distribusi temperatur permukaan di sepanjang fin, pengaruh diameter fin, dan pengaruh kecepatan fluida.

\section{A. Distribusi Temperatur}

Gambar 5 merupakan grafik distribusi temperatur permukaan fin $10 \mathrm{~mm}$ pada baris pertama dengan set point $50^{\circ} \mathrm{C}$. Baris pertama terdiri dari 4 fin dengan 2 fin terukur yaitu fin 9 dan fin 10. Dari grafik tersebut dapat diketahui bahwa masing-masing fin mempunyai trendline yang sama. Trendline grafik mengalami penurunan temperatur di sepanjang fin. Temperatur tertinggi terjadi pada posisi $\mathrm{x}=0$ $\mathrm{mm}$, kemudian temperatur menurun pada $\mathrm{x}=35 \mathrm{~mm}$, dan temperatur terendah pada posisi $x=70 \mathrm{~mm}$. Fin 9 mempunyai temperatur yang lebih tinggi daripada fin 10 pada setiap variasi kecepatan. Temperatur yang paling tinggi terjadi pada kecepatan fluida $2.64 \mathrm{~m} / \mathrm{s}$. Temperatur permukaan fin diameter $10 \mathrm{~mm}$ pada $\mathrm{x}=70 \mathrm{~mm}$ sebesar $43.73^{\circ} \mathrm{C}$ dan fin 10 sebesar $43.29^{\circ} \mathrm{C}$. Sebaliknya, temperatur terendah terjadi pada kecepatan fluida $4.2 \mathrm{~m} / \mathrm{s}$ dengan temperatur fin 9 sebesar $41.45^{\circ} \mathrm{C}$ dan fin 10 sebesar $40.94^{\circ} \mathrm{C}$.

Gambar 6 merupakan grafik distribusi temperatur permukaan fin $16 \mathrm{~mm}$ pada baris pertama dengan set point $50^{\circ} \mathrm{C}$. Dari grafik tersebut dapat diketahui bahwa masingmasing fin mempunyai trendline yang sama yaitu menurun di sepanjang fin. Temperatur permukaan fin 9 pada $\mathrm{x}=70 \mathrm{~mm}$ sebesar $46.60^{\circ} \mathrm{C}$ dan fin 10 sebesar $43.95^{\circ} \mathrm{C}$. Sebaliknya, temperatur terendah terjadi pada kecepatan fluida $4.2 \mathrm{~m} / \mathrm{s}$ dengan temperatur fin 9 sebesar $44.85^{\circ} \mathrm{C}$ dan fin 10 sebesar $41.66^{\circ} \mathrm{C}$.

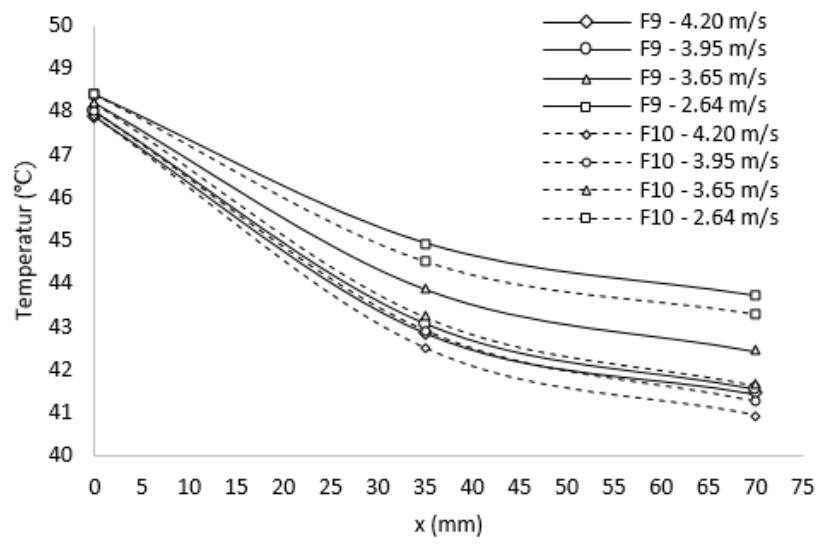

Gambar 5. Grafik distribusi temperatur permukaan sepanjang fin 10 mm pada baris pertama.

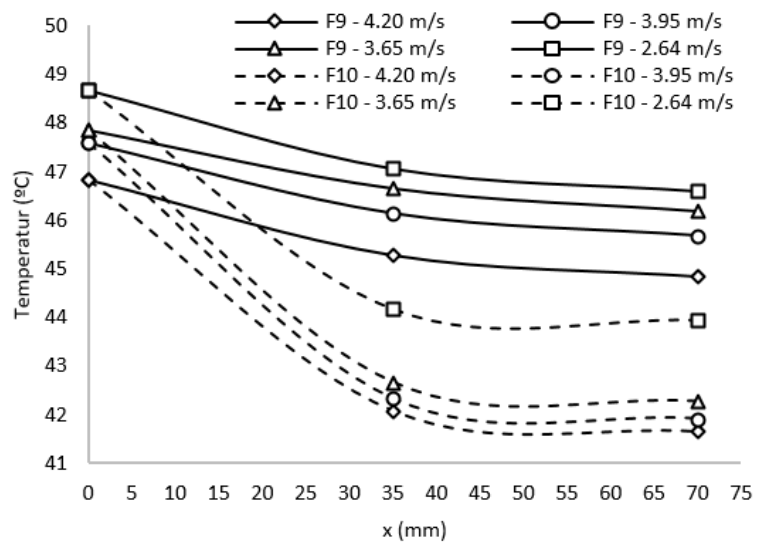

Gambar 6. Grafik distribusi temperatur permukaan sepanjang fin 16 mm pada baris pertama.

Gambar 7 merupakan grafik distribusi temperatur permukaan fin $10 \mathrm{~mm}$ pada baris kedua dengan set point $50^{\circ} \mathrm{C}$. Baris kedua terdiri dari 5 fin dengan 3 fin terukur yaitu fin 6, 7, dan 8. Ketiga fin tersebut mempunyai trendline menurun di sepanjang fin. Temperatur tertinggi terjadi pada fin 6, sedangkan temperatur fin 7 lebih tinggi daripada fin 8 . 
Pada kecepatan fluida $2.64 \mathrm{~m} / \mathrm{s}$ temperatur fin 6, 7, dan 8 secara berturut-turut pada $\mathrm{x}=70 \mathrm{~mm}$ adalah $43.94^{\circ} \mathrm{C}$, $42.51^{\circ} \mathrm{C}$, dan $41.84^{\circ} \mathrm{C}$.

Gambar 8 merupakan grafik distribusi temperatur permukaan fin $16 \mathrm{~mm}$ pada baris kedua dengan set point $50^{\circ} \mathrm{C}$. Trendline grafik tersebut menurun di sepanjang fin. Temperatur tertinggi terjadi pada fin 6, sedangkan temperatur fin 7 lebih tinggi daripada fin 8. Pada kecepatan fluida 2.64 $\mathrm{m} / \mathrm{s}$, temperatur fin 6,7 , dan 8 secara berturut-turut pada $\mathrm{x}=$ $70 \mathrm{~mm}$ adalah $46.75^{\circ} \mathrm{C}, 44.44^{\circ} \mathrm{C}$, dan $43.35^{\circ} \mathrm{C}$.

Gambar 9 merupakan grafik distribusi temperatur permukaan fin $10 \mathrm{~mm}$ pada baris ketiga dengan set point $50^{\circ} \mathrm{C}$. Baris ketiga terdiri dari 4 fin dengan 2 fin terukur yaitu fin 4 dan fin 5. Dari grafik tersebut dapat diketahui bahwa masing-masing fin mempunyai trendline yang sama. Trendline grafik menurun di sepanjang fin dengan temperatur tertinggi terjadi pada fin 4 yaitu sebesar $45.33^{\circ} \mathrm{C}$, sedangkan temperatur fin 5 sebesar $41.48^{\circ} \mathrm{C}$.

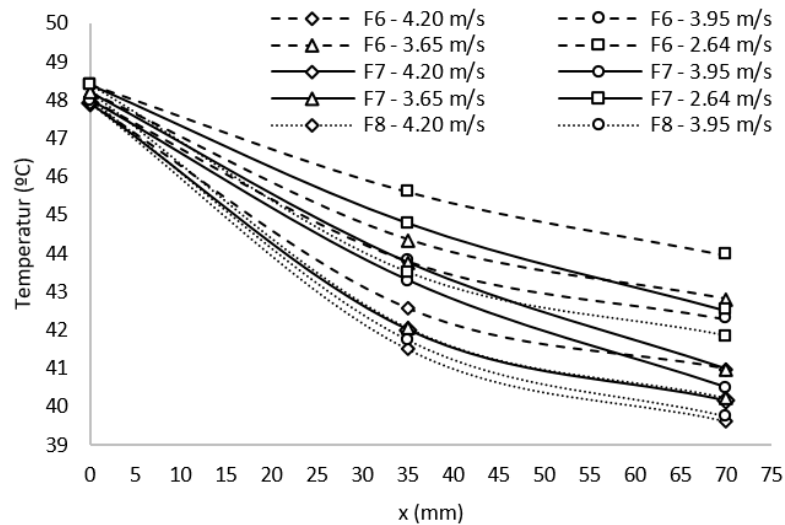

Gambar 7. Grafik distribusi temperatur permukaan sepanjang fin $10 \mathrm{~mm}$ pada baris kedua.

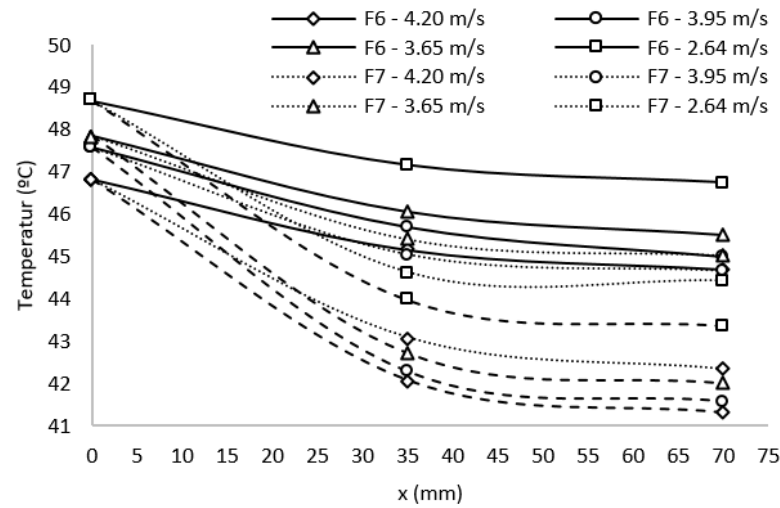

Gambar 8. Grafik distribusi temperatur permukaan sepanjang fin $16 \mathrm{~mm}$ pada baris kedua.

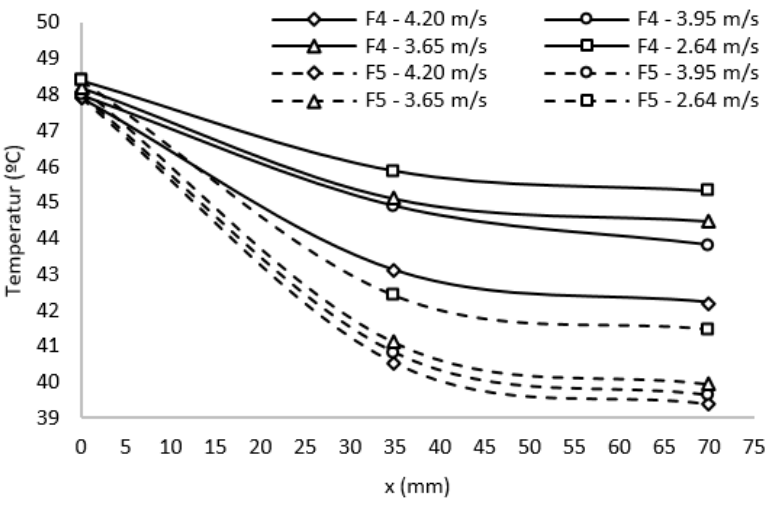

Gambar 9. Grafik distribusi temperatur permukaan sepanjang fin $10 \mathrm{~mm}$ pada baris ketiga.
Gambar 10 merupakan grafik distribusi temperatur permukaan fin $16 \mathrm{~mm}$ pada baris ketiga dengan set point $50^{\circ} \mathrm{C}$. Dari grafik tersebut dapat diketahui bahwa masingmasing fin mempunyai trendline yang sama. Trendline grafik menurun di sepanjang fin dengan temperatur tertinggi terjadi pada fin 4 yaitu sebesar $45.92^{\circ} \mathrm{C}$, sedangkan temperatur fin 5 sebesar $44.52^{\circ} \mathrm{C}$.

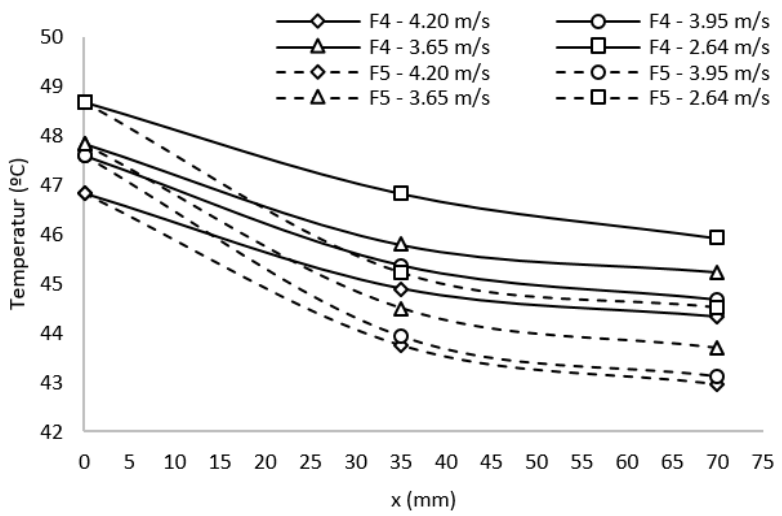

Gambar 10. Grafik distribusi temperatur permukaan sepanjang fin $16 \mathrm{~mm}$ pada baris ketiga.

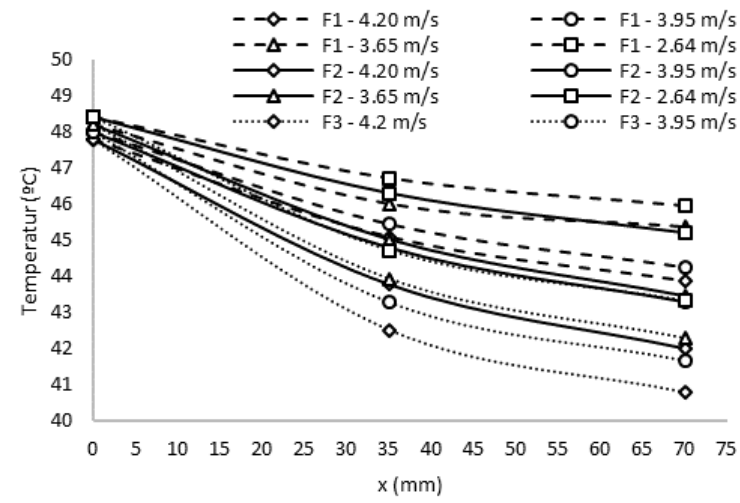

Gambar 11. Grafik distribusi temperatur permukaan sepanjang fin $10 \mathrm{~mm}$ pada baris keempat.

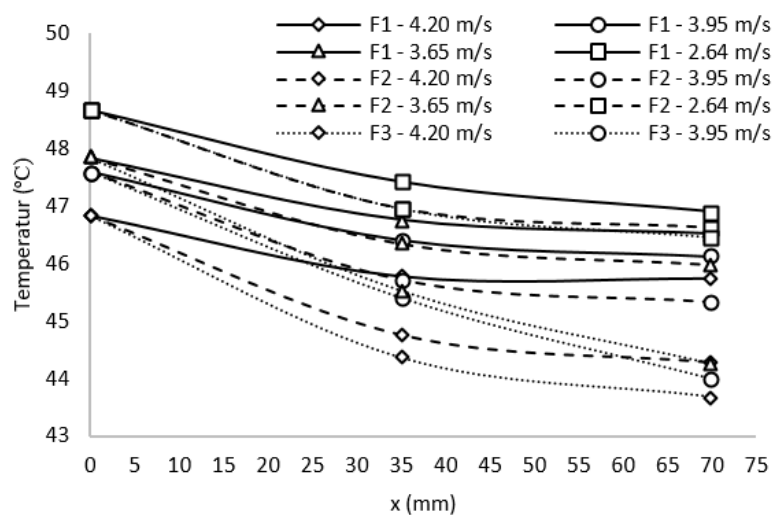

Gambar 12. Grafik distribusi temperatur permukaan sepanjang fin 16 mm pada baris keempat.

Gambar 11 merupakan grafik distribusi temperatur permukaan fin $10 \mathrm{~mm}$ pada baris keempat dengan set point $50^{\circ} \mathrm{C}$. Baris keempat terdiri dari 5 fin dengan 3 fin terukur yaitu fin 1, 2, dan 3. Ketiga fin tersebut mempunyai trendline menurun di sepanjang fin. Temperatur tertinggi terjadi pada fin 1 dan temperatur terandah terjadi pada fin 3 Pada kecepatan fluida $2.64 \mathrm{~m} / \mathrm{s}$, temperatur fin 1, 2, dan 3 secara berturut-turut pada $\mathrm{x}=70 \mathrm{~mm}$ adalah $45.97^{\circ} \mathrm{C}, 45.19^{\circ} \mathrm{C}$, dan $43.32^{\circ} \mathrm{C}$.

Gambar 12 merupakan grafik distribusi temperatur permukaan fin $16 \mathrm{~mm}$ pada baris keempat dengan set point $50^{\circ} \mathrm{C}$. Baris keempat terdiri dari 5 fin dengan 3 fin terukur 
yaitu fin 1, 2, dan 3. Ketiga fin tersebut mempunyai trendline menurun di sepanjang fin. Temperatur tertinggi terjadi pada fin 1 dan temperatur terandah terjadi pada fin 3 Pada kecepatan fluida $2.64 \mathrm{~m} / \mathrm{s}$, temperatur fin 1, 2, dan 3 secara berturut-turut pada $\mathrm{x}=70 \mathrm{~mm}$ adalah $46.89^{\circ} \mathrm{C}, 46.63^{\circ} \mathrm{C}$, dan $46.46^{\circ} \mathrm{C}$

Berdasarkan hasil eksperimen yang telah didapatkan, diketahui bahwa temperatur permukaan fin $16 \mathrm{~mm}$ mempunyai nilai yang lebih tinggi daripada temperatur fin 10 $\mathrm{mm}$. Kedua variasi diameter fin menunjukkan perilaku yang sama yaitu fin yang terletak di sebelah kiri mempunyai temperatur yang lebih tinggi daripada fin yang terletak di tengah dan sebelah kanan. Fin di sebelah kiri mempunyai temperatur yang lebih tinggi dikarenakan kecepatan fluida yang mengalir pada ducting sisi kiri lebih rendah dibandingkan di bagian tengah dan di sisi kanan. Kecepatan fluida yang lebih tinggi dapat membawa panas dari fin lebih besar dan menyebabkan terjadinya perpindahan panas yang lebih cepat. Oleh karena itu, fin di sisi kanan mempunyai temperatur yang lebih rendah daripada sisi yang lain.

Temperatur permukaan fin paling tinggi terjadi pada kecepatan fluida sebesar $2.64 \mathrm{~m} / \mathrm{s}$, kemudian mengalami penurunan berturut-turut pada kecepatan $3.65 \mathrm{~m} / \mathrm{s}, 3.95 \mathrm{~m} / \mathrm{s}$, dan $4.20 \mathrm{~m} / \mathrm{s}$. Semakin besar kecepatan fluida yang mengalir melalui fin, maka semakin besar pula panas yang dapat terbawa oleh fluida tersebut, sehingga temperatur fin menjadi lebih rendah.

\section{B. Pengaruh Kecepatan Fluida terhadap Perpindahan} Panas Fin

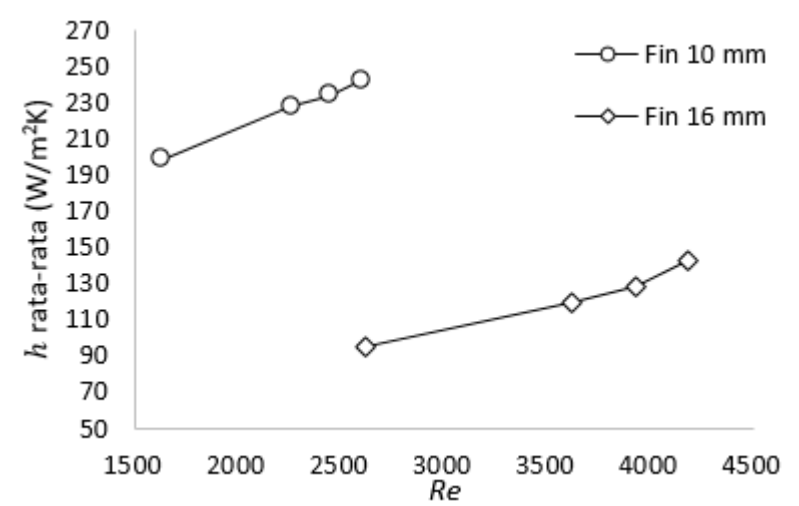

Gambar 13. Grafik Pengaruh Reynolds number terhadap koefisien konveksi perpindahan panas

Gambar 13 merupakan grafik pengaruh Reynolds number terhadap koefisien perpindahan panas konveksi. Grafik tersebut mempunyai trendline yang cenderung naik. Kecepatan fluida berpengaruh terhadap nilai Reynolds number. Semakin besar kecepatan fluida, maka Reynolds number akan semakin besar. Begitu sebaliknya, ketika kecepatan fluida kecil, maka nilai Reynolds number juga kecil. Berdasarkan eksperimen yang telah dilakukan, koefisien konveksi terbesar terjadi pada saat kecepatan fluida $4.2 \mathrm{~m} / \mathrm{s}$, yaitu pada fin $10 \mathrm{~mm}$ sebesar $242.43 \mathrm{~W} / \mathrm{m}^{2} \mathrm{~K}$ dan pada fin $16 \mathrm{~mm}$ sebesar $142.53 \mathrm{~W} / \mathrm{m}^{2} \mathrm{~K}$. Selain itu, Reynolds number mempunyai pengaruh terhadap besar Nusselt number seperti Persamaan 2, dimana Nusselt number merupakan fungsi dari Reynolds number. Nilai Nusselt number meningkat seiring meningkatnya Reynolds number.

Nilai koefisien koveksi rata-rata meningkat seiring bertambanhnya Reynolds number. Pada kecepatan fluida yang sama, nilai koefisien konveksi fin diameter $10 \mathrm{~mm}$ mempunyai nilai yang lebih tinggi daripada fin diameter 16 mm. Hal ini disebabkan oleh jarak antar fin $10 \mathrm{~mm}$ lebih lebar, fluida yang mengalir pada berkas fin diameter $10 \mathrm{~mm}$ lebih banyak, dan akan membawa panas lebih banyak daripada berkas fin diameter $16 \mathrm{~mm}$, sehingga perpindahan panas yang terjadi pada fin diameter $10 \mathrm{~mm}$ lebih baik daripada fin diameter $16 \mathrm{~mm}$

\section{KESIMPULAN DAN SARAN}

Kesimpulan yang didapatkan dari penelitian ini adalah distribusi temperatur di sepanjang fin menurun. Temperatur permukaan fin tertinggi terjadi pada baris keempat. Semakin tinggi kecepatan fluida yang melalui berkas fin, semakin rendah pula temperatur fin, oleh karena itu, temperatur terendah dicapai pada kecepatan $4.20 \mathrm{~m} / \mathrm{s}$ dan temperatur tertinggi terjadi pada kecepatan $2.64 \mathrm{~m} / \mathrm{s}$. Pada kecepatan yang sama, fin diameter $10 \mathrm{~mm}$ mempunyai koefisien konveksi yang lebih besar daripada fin diameter $16 \mathrm{~mm}$, yaitu $242.431 \mathrm{~W} / \mathrm{m}^{2} \mathrm{~K}$ dan $142.534 \mathrm{~W} / \mathrm{m}^{2} \mathrm{~K}$. Reynolds number terbesar terjadi pada kecepatan tertinggi yaitu $4.20 \mathrm{~m} / \mathrm{s}$. Semakin besar Reynolds number maka semakin tinggi koefisien konveksi yang terjadi.

\section{DAFTAR SIMBOL}

\begin{tabular}{ll}
$A, A_{s}$ & luas permukaan, $\mathrm{m}^{2}$ \\
$A_{c}$ & luas penampang, $\mathrm{m}^{2}$ \\
$A_{f f}$ & free flow area, $\mathrm{m}^{2}$ \\
$A_{t}$ & luas permukaan total, $\mathrm{m}^{2}$ \\
$c_{p}$ & panas jenis udara, J/kg. $\mathrm{K}$ \\
$h$ & koefisien perpindahan panas konveksi, W/m² $\mathrm{K}$ \\
$H$ & panjang fin, m \\
$k$ & konduktivitas termal, W/mK \\
$L$ & panjang, m \\
$L_{c}$ & panjang karakteristik, $\mathrm{m}$ \\
$\dot{m}$ & laju aliran massa udara, kg/s \\
$N_{x}$ & jumlah fin arah longitudinal \\
$N_{y}$ & jumlah fin arah transversal \\
$N_{x y}$ & jumlah total \\
$N u$ & bilangan Nusselt \\
$P r$ & bilangan Prandtl \\
$q$ & laju perpindahan panas, W \\
$Q_{i n}$ & panas masuk, W \\
$R e$ & bilangan Reynolds \\
$S_{D}$ & diagonal pitch, m \\
$S_{L}, S_{X}$ & longitudinal pitch, m \\
$S_{T}, S_{y}$ & transversal pitch, $\mathrm{m}$ \\
$T$ & temperature, $K$ \\
$V$ & kecepatan, m/s \\
$W$ & lebar, m \\
& \\
\hline
\end{tabular}

\section{DAFTAR PUSTAKA}

[1] M. A. J. Rasel, M. Z. Islam, and A. Hasanat, “Analysis of heat transfer characteristics under forced convection in a rectangular body with circular fins,” Am. J. Eng. Res., vol. 5, no. 10, pp. 311-316, 2016.

[2] D. Kamble, P. Gadhave, S. Gole, and M. Gole, “An experimental investigation of forced convection heat transfer coefficient using various pin fins,” IJIRST-International J. Innov. Res. Sci. Technol., vol. 2, no. 10, pp. 1-3, 2016.

[3] C. Mageswaran, R. Muthukumaran, R. Karthikeyan, and R. Rathnasamy, "Heat transfer and friction in rectangular duct with pinfin arrays,” Int. J. Eng. Res. Technol., vol. 5, no. 2, pp. 143-148, 2016

[4] F. P. Incropera, D. P. Dewitt, T. L., A. Bergman, and S. Lavine, Fundamentals of Heat and Mass Transfer, 7th ed. New York: John Wiley \& Sons Inc, 2011. 